\title{
Ocular changes associated with Giardia lamblia infection in children
}

\author{
A Corsi, C Nucci, D Knafelz, D Bulgarini, L Di Iorio, A Polito, F De Risi, \\ F Ardenti Morini, F M Paone
}

\begin{abstract}
Background-The protozoan disease giardiasis can cause ocular complications, including "salt and pepper" retinal changes.

Methods-Ophthalmic examinations were performed in 141 children (mean age 4.7 (SD 2.0) years) with active or past giardiasis diagnosed on the basis of microscopic examination of stool specimens or duodenal secretions-53 were newly diagnosed and untreated (group A), 50 had active infections in spite of metronidazole therapy (group B), and 38 had been successfully treated, with negative stool specimens for 1-3 years (group C). 300 children with no evidence of giardiasis were used as controls.
\end{abstract}

Results-Salt and pepper retinal changes (with normal electroretinographic findings) were diagnosed in $28(19.9 \%)$ of the patients with giardiasis (11 from group $A$, 10 from group $B$, and seven from group $C)$, including five pairs of siblings. In all subgroups, the children with retinal changes were consistently younger than those with normal retinas. In eight cases, the lesions could be visualised only with direct ophthalmoscopy.

Conclusion-Our findings indicate that asymptomatic, non-progressive retinal lesions are particularly common in younger children with giardiasis. This risk does not seem to be related to the severity of the infection, its duration, or the use of metronidazole but may reflect a genetic predisposition.

(Br f Ophthalmol 1998;82:59-62)

Servizio di

Gastroenterologia

Pediatrica,

Clinica Pediatrica,

Universita' di Roma

"Tor Vergata",

Rome, Italy

D Knafelz

D Bulgarini

L Di Iorio

A Polito

F De Risi

F Ardenti Morini

F M Paone

Correspondence to: Dr Carlo Nucci,

Dipartimento di Chirurgia Cattedra di Ottica

Fisiopatologica, Universita' di Roma "Tor Vergata", Vi Orazio Raimondo 800173 Roma, Italy.

Accepted for publication 27 August 1997 erated turnover of the mucosal epithelium and, as a result, changes in intestinal transit and absorption. $^{2-5}$
The infection is often asymptomatic in adults, but symptoms are much more common in children, in part due to the oro-faecal transmission and in part because of the immaturity of their immunological systems. ${ }^{1-6}$ The primary gastrointestinal symptoms consist of recurrent abdominal pain, diarrhoea, vomiting, and signs of malabsorption. Patients with giardiasis also present extraintestinal symptoms such as fever, maculopapular rashes, geographic tongue, pulmonary infiltrates, lymphadenopathy, polyarthritis, aphthous ulcers, and urticaria. ${ }^{6}$

The first description of ocular complications in patients with giardiasis was published by Barraquer in $1938 .^{7}$ This report included cases of iridocyclitis, choroiditis, and retinal haemorrhages. Cases of anterior and posterior uveitis and retinal vasculitis have subsequently been associated with the infection, ${ }^{8-12}$ and in 1990 Pettoello-Mantovani et $a l^{13}$ described a "salt and pepper" form of degeneration involving the retinal pigmented epithelium in children suffering from giardiasis.

In the present study, we evaluated the frequency of ocular manifestations in a group of Italian children with current or past giardiasis. To determine whether the course of the disease might be related to the appearance and/or severity of these complications, this frequency was analysed in light of the time of diagnosis, the duration of treatment, and the time interval that had elapsed since the infections had been cured.

\section{Patients and methods}

The study population comprised 141 children seen between January 1994 and March 1995 in the paediatric gastroenterology outpatient clinic of the Tor Vergata University Medical Centre in Rome. All had been diagnosed as having Giardia lamblia infections between 1991 and 1994. The children (64 males, 77 females) ranged in age from 9 months to 13 years (mean age 4.7 (SD 2.0) years). All had presented gastrointestinal symptoms. None of the children included in the study had current or past histories of other infections or metabolic diseases, and none had ever been treated with chloroquine, thioridazine, or chlorpromazine, which are known to cause ocular toxicity.

In children less than 3 years of age, the diagnosis of giardiasis was made after the parasite had been isolated from at least three fresh stool specimens (collected 3 hours or less before examination). In older children (that is, 3 years or older), diagnoses were based on examination of duodenal secretions collected with the Enterotest system (HDC Corporation, Moun- 

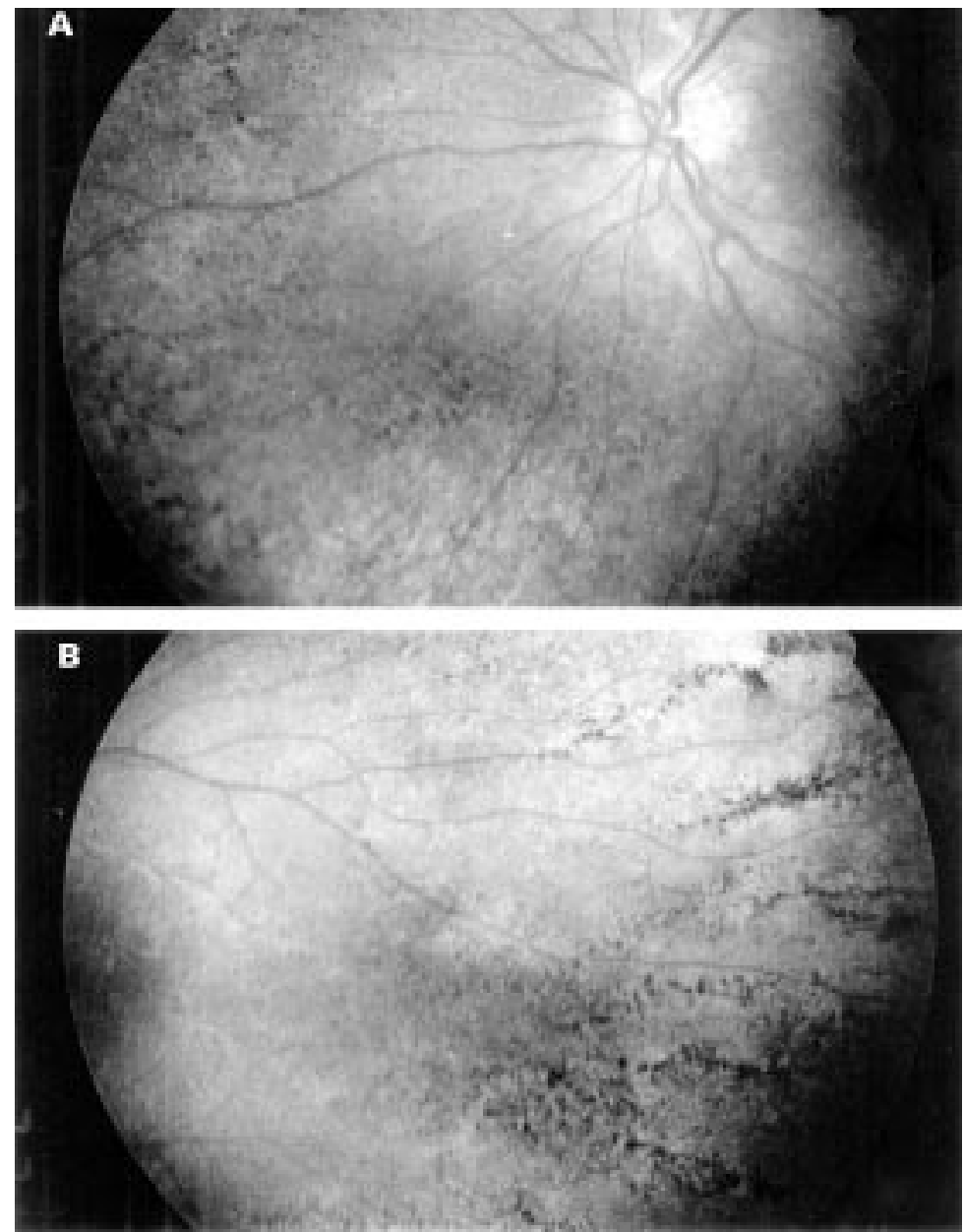

Figure 1 (A) and (B) Photographs showing typical "salt and pepper" appearance of the retina.

Table 1 Incidence of "salt and pepper" (SP) retinal degeneration among patients at different stages of infection and therapy

\begin{tabular}{llllll}
\hline Total number & $\begin{array}{l}\text { Number of } \\
\text { patients with } \\
\text { SP }\end{array}$ & $\begin{array}{l}\text { Age (SD) of } \\
\text { total group }\end{array}$ & $\begin{array}{l}\text { Age }(S D) \text { of } \\
\text { patients with } \\
\text { SP }\end{array}$ & Statistic \\
\hline Patients & 141 & $28(19.9 \%)$ & $4.7(2.0)$ & $3.5(0.4)^{\star}$ & $\mathrm{p}<0.05$ \\
Group A & 53 & $11(39.2 \%)$ & $4.1(0.3)$ & $3.2(0.3)^{\star}$ & $\mathrm{p}<0.05$ \\
Group B & 50 & $10(35.7 \%)$ & $4.0(0.5)$ & $2.7(0.5)^{\star}$ & $\mathrm{p}<0.05$ \\
Group C & 38 & $7(25 \%)$ & $5.8(0.8)$ & $4.2(0.4)^{\star}$ & $\mathrm{p}<0.05$ \\
Control & 300 & 0 & $4.7(2.0)$ & &
\end{tabular}

${ }^{\star}$ Denotes $\mathrm{p}<0.05$ versus age $(\mathrm{SD})$ total group. Group $\mathrm{A}=$ patients with giardiasis infection who did not received any treatment; group $\mathrm{B}=$ patients with giardiasis infection in spite of therapy; group $\mathrm{C}=$ patients who recovered from the giardiasis infection after treatment.

tain View, CA, USA). ${ }^{14}$ All patients underwent microbiological screening for the following pathogens: Salmonella, Shigella, Campylobacter, Yersinia, Escherichia coli, rotavirus, and adenovirus, ${ }^{15}$ If any pathogenic microorganisms, different from Giardia lamblia, were found the patient was excluded from the study.

The study group was divided into three subgroups. Group A comprised 53 children (mean age 4.1 (SD 0.3) years) who were studied immediately after diagnosis before any treatment had been started. Group B included 50 children (mean age 4.0 (0.5) years) who had been diagnosed as having giardiasis 12 months or more before our study. In spite of two or more cycles of treatment (metronidazole 5 $\mathrm{mg} / \mathrm{kg}$ three times a day for 7-10 days), all of these children presented positive stool speci- mens at the time of our evaluation. Group C consisted of 38 children (mean age 5.8 (0.8) years) with previous Giardia lamblia infections that had been successfully treated with one or more cycles of metronidazole therapy. In follow ups that ranged from 1 to 3 years, periodic examination of stool specimens had failed to reveal any signs of the protozoan.

The study also included a control group comprised 300 children selected between the ones who attended our outpatient clinic in the same period as the study group. They all came from the same geographical area and had socioeconomic, nutritional characteristics ${ }^{16} 17$ similar to those in the study group. We excluded from the control group all the children who had a positive medical history for infectious diseases (apart for upper respiratory tract infections) and metabolic diseases. They also had never been treated with chloroquine, thioridazine, or chlorpromazine which, as stated earlier, are known to cause ocular toxicity. One hundred and fifty of these children (77 males, 73 females aged 11 months to 14 years; mean age 4.7 (2.1) years) had no gastrointestinal symptoms whatsoever; the remaining 150 (76 males, 74 females aged 9 months to 14 years; mean age 4.7 (1.9) years) were suffering from food allergy, or coeliac disease, or gastrooesophageal reflux, or toddler diarrhoea and had symptoms such as diarrhoea, vomiting, and/or abdominal pain. All of the control subjects were negative for giardiasis based on microscopic examination of stool specimens (three specimens) and/or duodenal secretions examined at least three times in a period of 3 months.

All the children in both the study and control groups underwent an ophthalmic examination that included measurement of visual acuity, studies of ocular motility, slit lamp examination of the anterior chamber, and direct and indirect ophthalmoscopic examination of the fundus after induction of mydriasis with cyclopentolate.

All the children in both the study and control groups were examined independently by two ophthalmologists. The first (AC) was aware of the child's enrolment in the study but not his/her group origin (that is, case or control). They were then examined by a second ophthalmologist (CN) who was unaware of the nature of our study or the case/control status of the child. Ocular changes were diagnosed only when detected by both examiners. Electroretinography (ERG) was also performed whenever fundus changes were observed.

\section{Results}

The visual acuity examination of the giardiasis group revealed a mean refractive error of -1.0 (SD 0.5) D. Studies of ocular motility and anterior chamber examinations were unremarkable in all 141 children. Changes in the retinal epithelium compatible with a salt and pepper appearance (Fig 1A and 1B) were confirmed by both ophthalmologists in 28/141 (19.9\%) children (15 males, 13 females; mean age $3.5(0.4)$ years) (Table 1). Three other 
cases were excluded from analysis because the finding was recorded by only one of the examiners. These lesions presented as punctate areas of hyperpigmentation against a lighter coloured fundus. The changes were more prevalent in the mid periphery of the upper and lower retinal quadrants. Involvement was bilateral in 25/28 cases. In 20 of these children, the lesions could be visualised with both indirect and direct ophthalmoscopy. In the remaining eight, the retinal changes were revealed only with the latter examination. Electroretinograms were normal in all of these 28 children. In one case, both examiners noted additional retinal damage that could be attributed to previous chorioretinitis.

Eleven (39.2\%) of the 28 children with retinal lesions were from group A, 10 (35.7\%) were from group $\mathrm{B}$, and seven $(25 \%)$ belonged to group $\mathrm{C}$ (Table 1). The group with retinal changes also included five pairs of siblings. In some cases from the latter group, the infection had been diagnosed 3 years before our study. Table 1 shows the ages of the 28 children with positive findings and those of children whose fundus examinations were normal. In all three of the subgroups, the children with retinal lesions were significantly younger than those without lesions ( $\mathrm{p}<0.05$, Student's $t$ test), and the prevalence of positive findings was directly proportional to the mean age of the subgroup. There were no differences among the three subgroups as far as the clinical features or extension of the retinal involvement were concerned. In patients with active infections (groups A and B), there was no correlation between the faecal parasite count and the presence of retinal lesions.

In the 300 children in the control group, neither of the examiners found any retinal lesions of the type observed in the giardiasis group.

\section{Discussion}

The association between Giardia lamblia infection and ocular changes has been described by a number of authors. ${ }^{7-12}$ In 1990 PettoelloMantovani et al described eight cases of salt and pepper retinal degeneration in a group of 90 children with active giardiasis $(8.8 \%) .{ }^{13}$ In our study, conducted on an even larger population of paediatric giardiasis patients, the percentage of children with these retinal findings was even higher (19.9\%), which may reflect the younger age of the children we studied (mean 4.7 years $v 6.9$ years in the previously cited study). The higher frequency that emerges from our study may also be related to our use of both indirect and direct ophthalmoscopy. The higher magnification that can be achieved with the latter approach is often necessary to detect the subtle changes that characterise this type of retinal alteration. In fact, over one fourth of the children with salt and pepper lesions presented normal findings on indirect ophthalmoscopy.

The typical salt and pepper lesion is represented by punctate areas of normal or hyperpigmentation on a lighter, yellow-pink retina. ${ }^{18}$ In the children we examined, the lesions were more visible at the posterior pole, where there were distributed along the paths of the major blood vessels. These lesions differ from those of the more severe disease known as retinitis pigmentosa, in which the pigment granules are generally distributed in an osteoblast pattern around blood vessels. ${ }^{18}$ Salt and pepper lesions are thought to be caused by damage to or necrosis of the cells of the retinal pigment epithelium (represented clinically by the paler areas of the retina) with the release of pigment granules that migrate to the deeper retinal layers, where they can be seen as blackish dots. ${ }^{18}$

Similar findings have been described in other diseases as well, including cystinosis and various types of infection (for example, congenital syphilis, rubella, toxoplasmosis, and onchocerciasis). ${ }^{18}$ It has also been reported following the use of antimalarial drugs, phenothiazine, iodinated substances, and oral contraceptives. ${ }^{19}$

The mechanisms underlying the ocular lesions associated with giardiasis are currently obscure. Although microscopic studies on ocular tissues have never been performed, most authors exclude the possibility of direct invasion by the parasite. Indeed, the protozoan has never been isolated from any of the lesions caused by this disease, including urticaria, which is the manifestation that most strongly resembles the retinal arteritis and ocular inflammation seen in patients with ocular involvement. The retinal changes associated with giardiasis are more than likely caused by immune mechanisms. Wania reported that circulating immune complexes were found in all of the patients with ocular complications he examined. ${ }^{20}$ In addition, histological examination of urticarial lesions caused by giardiasis have demonstrated the presence of infiltrates composed of polymorphonuclear cells, lymphocytes, and eosinophils. ${ }^{10}$ It is possible that small children are more susceptible to this type of damage because of the immaturity of the retinal epithelium cells. This hypothesis is compatible with our observation of a higher frequency of ocular complications among the younger children of all three subgroups in the present study.

The group of patients with retinal manifestations included five pairs of siblings. Recent reports have linked giardiasis to certain HLA istotype ${ }^{21}$; since retinal pigmented epithelium degenerations are often genetically transmitted, ${ }^{18}$ it is therefore possible that the appearance of retinal complications depends, in part, on a genetic predisposition.

An analysis of the data from subgroups A (untreated, recently diagnosed infections) and B (long standing infections resistant to therapy) failed to reveal any significant differences in terms of either the prevalence or the severity of the retinal lesions found. This finding suggests that the development of this type of retinal change does not depend on either the severity or the evolution of the infection. Moreover, the observation of retinal lesions in group A (children who had not been treated at all) confirms previous reports that metronidazole 
does not influence the appearance or the evolution of these lesions. The retinal changes were found with a similar frequency among the children of group C, whose infections had been successfully eliminated 1-3 years before our study, indicating that the retinal lesions do not progress (or regress) with time.

These lesions do not appear to cause functional changes in the retina, since electroretinographic findings were normal in all of the children with retinal lesions although this conclusion will have to be confirmed in long term follow up. However, the absence of ERG changes is also important from a diagnostic point of view, since it distinguishes the salt and pepper changes from progressive forms of retinal epitheliopathy that carry a poorer prognosis.

The results of this study demonstrate that structural alterations of the retinal pigment epithelium are the most common ocular findings in paediatric patients with current or past giardiasis. Both ophthalmologists and paediatricians should be aware of this link when interpreting retinal findings in children, especially those from areas in which the infection is endemic.

1 Pickering LK, Engelkirk PG. Giardia lamblia. Pediatr Clin North Am 1988;35:565-72.

2 Holberton DV. Fine structure of the ventral disk apparatus and the mechanism of attachment in the flagellate Giardia muris. F Cell Sci 1973;13:11-41.

3 Janoff EN, Taylor DN, Echeverria P, Glode MP, Blaser MJ Serum antibodies to Giardia lamblia by age in populations in Colorado and Thailand. West $\mathcal{F}$ Med 1990;152:253-6. 4 Erlandsen SL, Mayer EA. Giardia and giardiasis: biology,
pathogenesis and epidemiology. New York: Plenum Press pathogenesis and $1984: 379-400$.

5 Erlandsen SL, Chase DG. Morphological alterations in the microvillous border of villous epithelial cells produced by intestinal microorganisms. Am f Clin Nutr 1974;27:127786

6 Webster BH. Human infection with Giardia lamblia. An analysis of 32 cases. Am $f$ Digest Dis (New Series) 1958;3:64-71

7 Barraquer I. Sur la coincidence de la lambliase et de certains lesions du fond de l'oeil. Bull Soc Pathol Exot (Paris) 1938; 31:55-8.

8 Carrol ME, Anast BP, Birch CL. Giardiasis and uveitis. Arch Ophthalmol 1961;65:775-8.

9 Djabri SE, Diallinas N. L'importance de la lambliase comme facteur etiologique dans le choriorètinite centrale sèreuse. Ophthalmologica 1964;147:264-72.

10 Knox DL, King J. Retinal arteritis, iridocyclitis and giardiaKnox DL, King J. Retinal arteritis, i
sis. Ophthalmology 1982;89:1303-8.

11 Druault Toufesco N. Les lèsions maculaires en rapport avec le parasite intestinaux. Bull Soc Fr Ophtal 1960;73:145-51.

12 Collier M, Adias L. Lambliase et èmorragie du vitrè. Bull Soc Med Pau 1961;43:133-9.

3 Pettoello-Mantovani M, Giardino I, Magli A, di Martino L, Guandalini S. Intestinal giardiasis associated with ophthalmologic changes. F Pediatr Gastroenterol Nutr 1990;11:196200.

14 Beal C, Viens P, Grant R, Hugues JM. A new tecnique for sampling duodenal contents. Am f Trop Med Hyg 1970;19: 349-52.

15 Lennette EA. Manual of clinical microbiology. Washington DC: American Society of Microbiology, 1985.

16 World Health Statistics Annual. Global overview. Vital statistics and life tables. Environmental health. Geneva: WHO, tics and

17 Gilli G. Igiene dell'ambiente e del territorio. Demografia, prevenzione e sanità pubblica. Turin: Edizioni Medico Scienprevenzione e san

18 Duke-Elder S. Disease of the retina. In: Duke-Elder S, Dobree JH, eds. System of ophthalmology. London: Henry Kimpton 1967:260-533.

19 Bec P, Ravault M, Arnè JL, Trepsat C. Changes in the fundus periphery due to toxic substances. In: The fundus periphery. New York: Masson 1980:418-23.

20 Wania JH. De Ocampo lecture. The eye and intestinal parasitic diseases. In: Shimizu K, ed. Current aspects in ophthalmology. Amsterdam: Elsevier Science, 1992:1-7.

21 Roberts-Thomson IC, Mitchel GI Genetic studies in human and murine giardiasis. Gut 1980;21:397-401. 